\title{
ECO-FRIENDLY MICROWAVE DYEING WITH NATURAL DYES
}

N.S.ELSHEMY and K.HAGGAG

Textile Research Division National research center, El-Behos St., Dokki, 12311, Cairo, Egypt

\begin{abstract}
The dyeing of cotton and viscose fabrics using turmeric and tea as natural dyes was investigated by both conventional and microwave heating methods. The extractability of turmeric and tea from natural origin using microwave was evaluated in comparison with traditional heating. The results of dye extraction indicate that microwave power is rather effective than traditional heating at low concentration and short time. Factors affecting dyeability of fabrics such as dyeing time, dye concentration, microwave power, and the aid of mordant were studied. The results of fastness properties of the dyed samples were good to excellent. The isotherm of dyeing revealed that the enhanced of dye uptake achieved in the second phase of dyeing (diffusion phase). The values of dyeing rate constant, half dyeing time and dye affinity were calculated and discussed.
\end{abstract}

Keywords: Microwave, cellulosic fibers, natural dyes, turmeric, tea, dyeing.

\section{Introduction}

The story of natural colored is not new. It started long back around five thousand years ago. The development of inexpensive dyes in numerous colors and shade pushed it into the back seat. The problems associated with exploration of newer sources of natural dyes are:

1. poor harvesting and post harvesting treatment practices.

2. Inefficient processing techniques lead to low yields and poor quality product.

3. lack of search on development of high yielding variety of dye yield plants.

4. lack of facilities to access latest technologies and market information.

Many synthetic dyes may lead to various harmful by product during their manufacture. A number of azoic dyes, which release carcinogenic amines, have already banned by most of countries. Moreover, the effluent discharged from dyeing units is also causing a lot of concern. There is an increasing realization in the textile industry as well as among the textile consumers to develop and demand eco-friendly methods of dyeing textiles. Natural dyes offer an important alternative in these regards, as these are safe in use with minimum health hazards and cause less disposal problem (Burnett Philip, 1995). Some of natural dyes constituents are antiallergent and hence proved to be safe for body contact (Glover Band piero J.H., 1993). Most of the naturally dyes materials are non-toxic, there for non-hazardous to health. 
Tea plants are classified as camellia siensisvariety senses and variety assamica. There are six types of tea: green, yellow, dark, white, oolong and black tea. This classification based on the processing methods employed, the degree of fermentation and the oxidation of the Polyphenol present in tea. The different class compounds found in tea include tannic acid, amino acid, caffeine, carbohydrate, arytenoids, chlorophyll, lipids, minerals, nucleotides, organic acids, polyphenol, saponins, unsaponifiable compounds and volatile compounds (Roy Teranishi and Irwin Horntein, 1995).

Of the polyphenol, Catechine are the principle colorant species. The chemical structure of Catechine to be epicatechine (I), epicatechine gal late (II), epicatechine (III), and epiallocatechine gall ate (IV), and named the two gal late "tea tannin I" and “tea tannin II” respectively (M. Tsujimura; Nippon Nogikagaku Kaishi 1934, E.G.Tsatsaroni and Ic Eleftheriadis 1994)

Turmeric or Carcumin is historically one of the most famous and brightest of naturally occurring yellow dyes. It extracted from the fresh or dried Rhizomes of turmeric. Curcumin is the only natural pigment belonging to diaroylmethan group. It is diferuloyl- methane.<smiles>COc1cc(C=CC2CC(=O)CC(=O)C2)ccc1O</smiles>

\section{(Curcuma Tinctoria, Diferuloye-methane, C.I.Natural Yellow 3)}

Srinivasam et.al. Suggested that the natural dye Curcumin is accompanied by minor amount of structurally similar sterioasymeric Curcumin he separated three pigment from an extract of turmeric, namely: diferuloylmethan having M.P. $183^{\circ} \mathrm{C}$, another compound of M.P. $168^{\circ} \mathrm{C}$, which probably may be (p-hydroxyl cinnamoyl) Feruloyl methane and bis (p- hydroxyl cinnamoyl)-methane having M.P. $224^{\circ} \mathrm{C}$ (M.D. Teli, Roshan panl\&P.D. pardeshi. 2000).

While cost presents a major barrier to wider use of microwave in textile industry, an equally important barrier is the lack of understanding of how microwaves interact 
with materials during heating process. Microwave energy has several possible benefits in textile processing ( $\mathrm{M}$. Tsujimura; Nippon Nogikagaku Kaishi). Substitution of conventional heating methods by microwave irradiation may result in faster and more uniform heating, more compact processing machinery requiring less space, and less material in process at a particular time.

Microwave heating can have certain benefits over conventional ovens:

- Reaction rate acceleration

- Milder reaction conditions

- Higher chemical yield

- Lower energy usage

- Different reaction selectivity

The present study focused on the dyeing of Cotton and Viscose with aqueous tea and turmeric with three different mordanting methods, pre ., simultaneous- and post mordanting using microwave heating and compared the result with conventional techniques.

\section{Experimental}

\section{Materials}

- A commercial sample of black tea (Lipton GET leaf tea powder, marketed by Hindustan lever limited, Mumbai, India) was used.

- Commercial sample of turmeric used as a yellow color. It supplied from commercial market.

- Mill scoured 100\% Cotton and 100\% viscose fabric supplied by Miser Co. for spinning and weaving (Mehalla El-kubra). Cotton and viscose were scoured to a bath containing $0.5 \mathrm{~g} / \mathrm{L}$ sodium carbonate and $2 \mathrm{~g} / \mathrm{L}$ non ionic detergent at $45^{\circ} \mathrm{C}$ for $30 \mathrm{~min}$, prior to mordanting or dyeing. The fabrics then thoroughly washed with clean tap water and air-dried at room temperature.

\section{Methods}

\section{Conventional Extraction}

Conventional extraction was carried out in $100 \mathrm{ml}$ boiling distilled water using varying amount of tea or turmeric (5-15\%) for different time intervals (15-120 min). The mixture was stirred, heated, allow stand for night and filtered. The filtrated solution used for dyeing.

\section{Microwave extraction}


Microwave extraction was carried out as above in $100 \mathrm{ml}$. distilled water using varying amount of tea and turmeric (5-15\%) using different microwave power (3090 watt) for different time intervals (15-60 min). The mixture was stirred, heated, allow stand for night and filtered. The filtrated solution used for dyeing.

\section{Dyeing procedure}

In a dye bath containing $10 \%$ of tea and $8 \%$ of turmeric with liquor ratio $50: 1$, cotton and viscose fabric were dyed using conventional heating $(\mathrm{CH})$ and microwave irradiation (MW) at different $\mathrm{pH}$ values (2-9) for different duration 15$120 \mathrm{~min}$ at the boiling. The effect of mordant added (namely Alum, Copper sulphate and Iron sulphate) to the dye bath was also conducted in a comparative manner of both MW and $\mathrm{CH}$ methods.

The dyed samples (with or without mordant) were rinsed with cold water followed by soaping with $2 \mathrm{~g} / \mathrm{l}$ nonionic detergent (Hostapal CV. Clariant) at $60^{\circ} \mathrm{C}$ for $30 \mathrm{~min}$ then rinsed squeezed finally dried at room temperature.

\section{Measurements:}

Color strength

The reflectance of the dyed samples was measured on a Perkin Lambda 3B UV/Vis spectrophotometer. Relative color strength (K/S values) was determined using the Kubelika-Munk equation (Perkin R.M. and Catlow N, 1984).

\section{UV/Vis Absorption spectra}

The UV/Vis absorption spectra in water were recorded using a Shimadzu UV/Vis absorption spectrophotometer. The quantity of dye uptake was estimated using the following equation:

$$
\mathrm{Q}=\left(\mathrm{C}_{0}-\mathrm{C}_{1}\right) \mathrm{V} / \mathrm{W}
$$

Where $\mathrm{Q}$ is the quantity of dye uptake $(\mathrm{mg} / \mathrm{g}), \mathrm{C}_{0}$ and $\mathrm{C}_{1}$ are the initial and the final concentration of dye in solution $(\mathrm{mg} / \mathrm{L})$ respectively, $\mathbf{V}$ is the volume of dye bath (L) and $\mathbf{w}$ is the weight of the fiber (g). The concentrations of yield solution were determined after reference to the respective calibration curve of the tea and turmeric dye using Lamber-Beer law. 


\section{Tensile strength}

The tensile strength and elongation at break (warp) determined by the strip method according ASTMD-225666T (ASTM Designation; D.5035-90).

\section{Fastness testing}

The dyed samples were tested according to ISO standard method. The specific tests were color fastness to washing, ISO 105-E04 (1989). Light fastness testes carried out by using Tara Fastness tester (Johnson A). The color change of the samples assessed against the appropriate blue scale.

\section{Result and Discussion}

\section{Dye extraction}

\section{Effect of dye amount}

Comparative extraction of tea and turmeric dye using $\mathrm{CH}$ as well as $\mathrm{MW}$ methods at $100^{\circ} \mathrm{C}$ and the extent of extractability was monitored spectrophotometrically at $\lambda \max 330$ for tea and 425 for turmeric. Fig. 1 shows that as the dye amount\% increase, the absorption of the dye extract increase when using both techniques ( $\mathrm{CH}$ and $\mathrm{MW}$ ) with much higher values at all points in MW cases as expected. The maximum extractability with attained in $10 \mathrm{~g} / 100 \mathrm{ml}, 8 \mathrm{~g} / 100 \mathrm{ml}$ distilled water for tea and turmeric respectively when use microwave heating, while it was $12 \mathrm{~g} / 100$ distilled water for both dyes when using traditional heating.

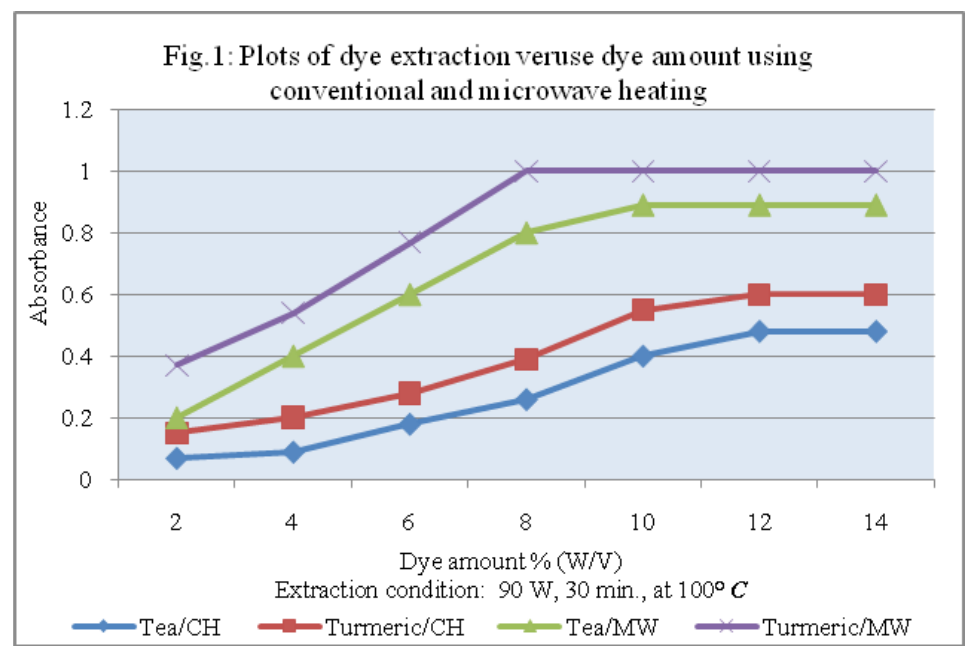

\section{Effect of extraction time}


MW and CH extraction of tea (10 and $12 \mathrm{~g} / 100 \mathrm{ml}$ distilled water) and turmeric (8 and $12 \mathrm{~g} / 100 \mathrm{ml}$ distilled water) respectively were carried out for different times intervals (10 - $45 \mathrm{~min}$ ) for MW and (15 - $90 \mathrm{~min})$ for CH. Fig. 2 and 3 shows the rate of dye extraction by $\mathrm{MW}$ and $\mathrm{CH}$ heating, from figure we can be observed that the dye extraction is higher in MW than that of $\mathrm{CH}$ to reveal maximum dye extraction after 30 min for tea and 35 for turmeric, it is worth that the absorption of extract causing MW $(0.88,0.95)$ after $30 \mathrm{~min}$, while when using $\mathrm{CH}$ it was only 0.69 and 0.75 after 70 and 80 min for tea and turmeric respectively. However, prolonged extraction time using $\mathrm{CH}$, may lead to degradation which associated with decreasing the absorbance of the extract.
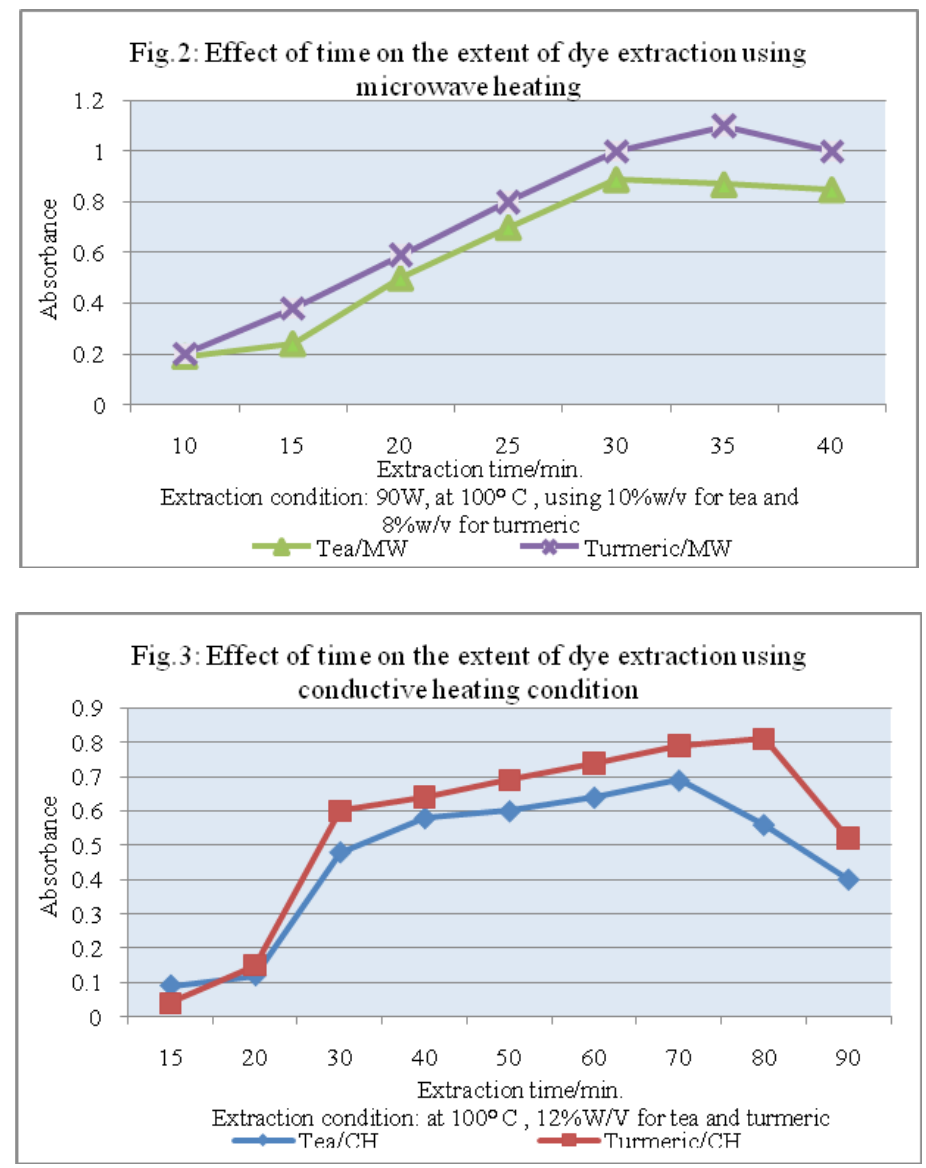

\section{Effect of microwave power on dye extraction}


ECO-FRIENDLY MICROWAVE DYEING WITH NATURAL DYES

The effect of microwave power on dye extractability of tea and turmeric was conducted at different power levels (30 -90 Watt). As shown in Fig. 4, The absorption of the extract increase with increasing power level up to 80 and 90 Watt for tea and turmeric respectively, which the maximum extraction was attained. The result of the dye extraction emphasize the enhancement effect of microwave power, which helps in accelerate the dye extraction from natural source by virtue of absorption and dye dispersion (microwave gives a uniform exposure to any materials moved through it).

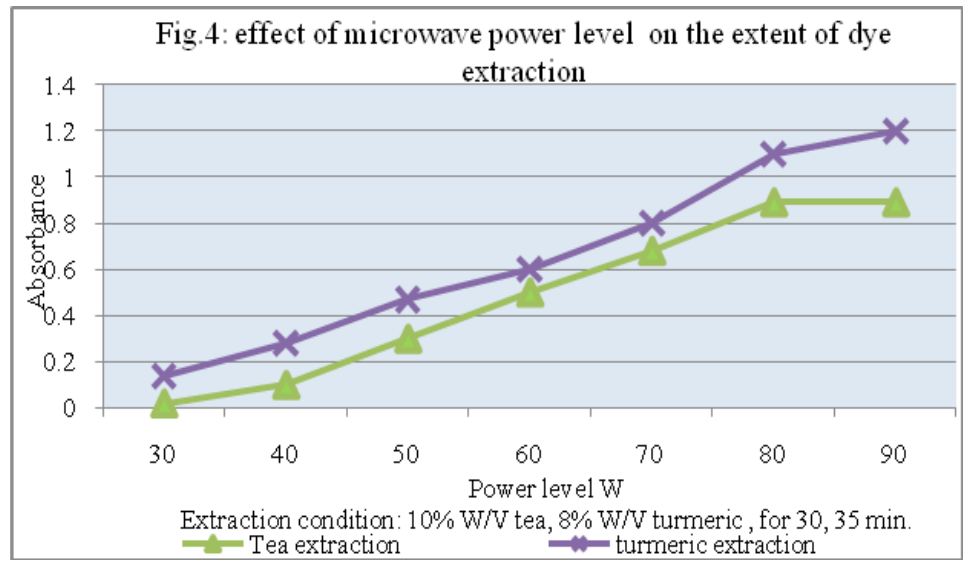

\section{Dyeing \\ Effect of microwave power level}

Increasing temperature, increase the reaction rates, and the rate of diffusion of dyes into fabric. The choice of microwave based on that attainment of desired temperature is faster in microwave as compared to conventional heating. As shown in Fig. 5 the color strength of dyed fabrics seemed to be directly proportional with power supplied. This behavior emphasized again the assisting effect of MW power on the dyeability of cotton and viscose fabric with tea and turmeric as natural dyes. This assistance can be explained as the microwave field energy will be converted to heat by different amount in different parts of the system domains. This in homogeneous energy dissipation means selective heating of different parts of the fabric is possible, and may lead to temperature gradients between them.

Nevertheless, the presence zones with a higher temperature than others (called hot spots) must be subjected to the heat transfer processes between domains, where the 
rate of heat conduction is high between system domains, hot spots would have no long-term existence as the components rapidly reach thermal equilibrium.

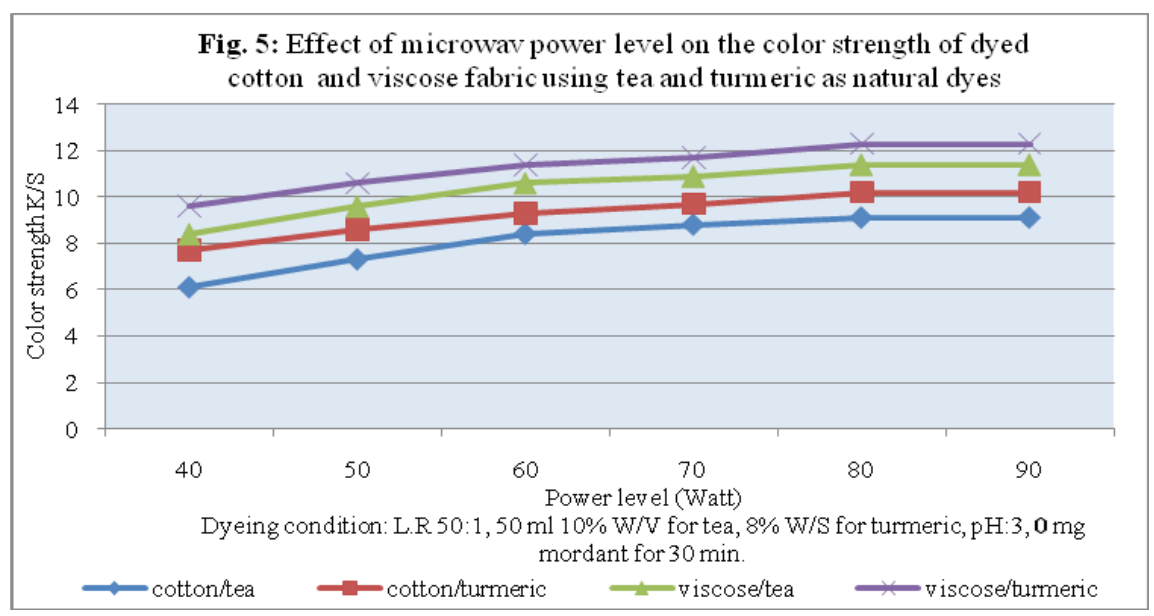

\section{Effect of dyeing time}

The effect of dyeing time was conducted at high concentrarion of the dyes (10 $\mathrm{g} / 100 \mathrm{ml}$ for tea and $8 \mathrm{~g} / 100 \mathrm{ml}$ for turmeric in case of MW and $12 \mathrm{~g} / 100 \mathrm{ml}$ for both dye in case of $\mathrm{CH}$ heating). Fig 6 and 7 indicat that the color strength increased as the dyeing time increas in both $\mathrm{MW}$ and $\mathrm{CH}$ heating associating with slightly higher K/S values at all point using MW. A plateau is attained after $40 \mathrm{~min}$ for tea and 50 min for turmeric in both fabric in MW, while it attained after $110 \mathrm{~min}$. for both dyes to cotton and 100 min for viscouse fabric in case of $\mathrm{CH}$. The enhancement effect due to the microwave irradiation may make more pronounced the non-uniform temperatue distribution with certain geometries. This lead to giving a temperature gradient inside the dyeing sample with the opposite directions to that in conventional dyeing process. The temperature inside the fabric slab becomes higher than it is on the surface so the diffusion and thermo-diffusion gradiant lead in the same direction and dyeing rate increases. Generlly, the increase in dye uptake can be explaned by fibre swelling and hence enhanced dye diffusion. 

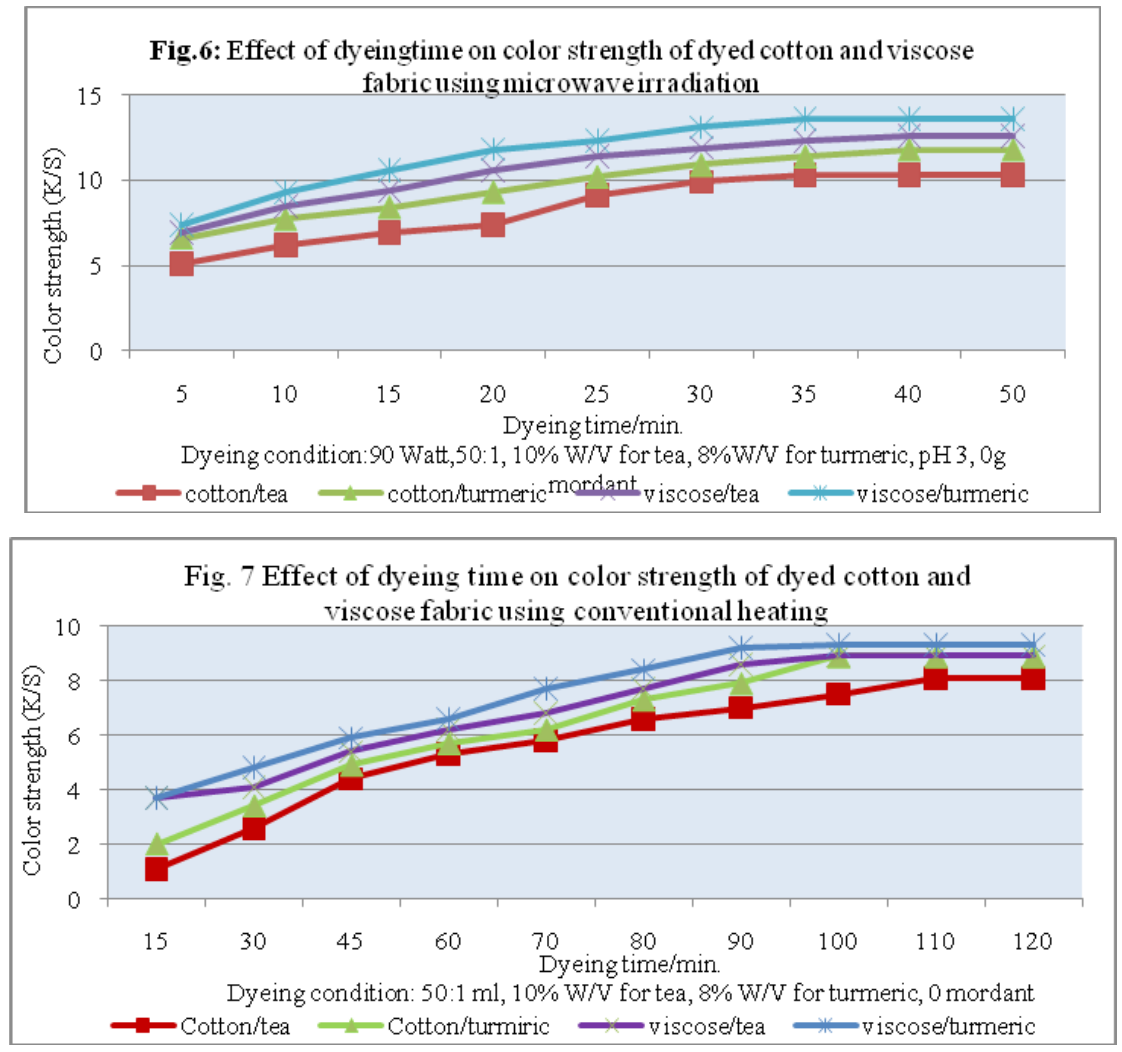

\section{Effect of pH}

Fig. 8 and 9 shows that the $\mathrm{pH}$ values of the dye bath have a considerable effect on the dyeability of cotton and viscose fabric with tea and turmeric under both MW and $\mathrm{CH}$ conditions. It is clear that MW has improved the dyeability of cotton fabric at $\mathrm{pH} 4$ when tea used as natural dye, while when used turmeric it was $\mathrm{pH} 4.5$, but in viscose fabric it was $\mathrm{pH} 3.5$ for both dyes. In case of conventional heating it was at 5.5 and 6.0 for both substrate. From Fig. 8 and 9 we can observed that the maximum color depth was observed at mild acidic condition using both MW and $\mathrm{CH}$ heating. (Ht Deo and BK Desai).However, the dye uptake decrease with increase $\mathrm{pH}$ from neutral to alkaline medium. 

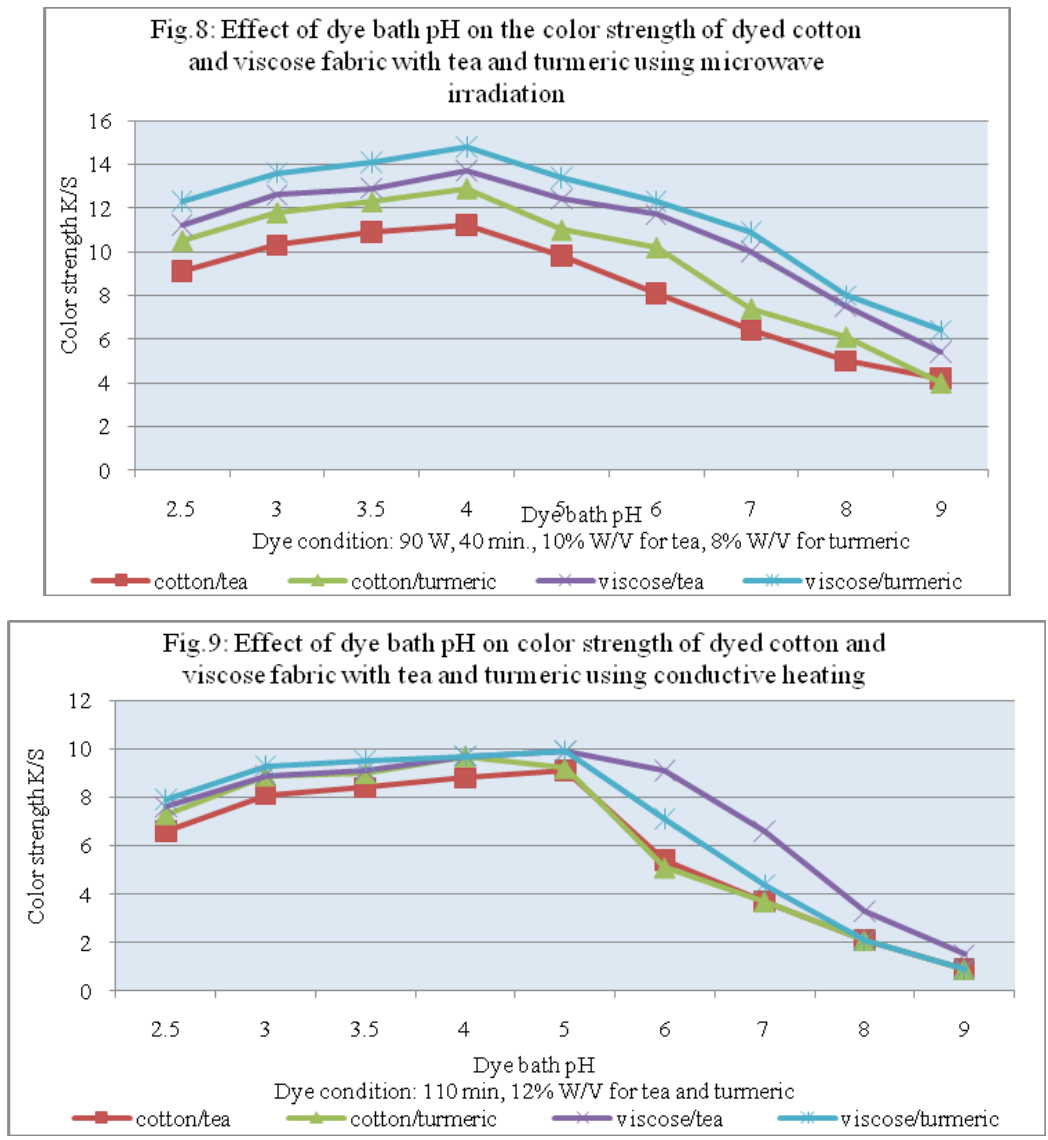

\section{Effect of mordant salt addition}

In the dyeing of textiles fibers with natural dyes, mordant play an important role. Usually a metal salt has substantively for both the colorant and the fiber, and forms an insoluble complex with the dye on the substrate. The effect of different mordant on the depth of shade on cotton and viscose dyed with tea and turmeric was studied. From Table 1 it was observed that, from the dyeing techniques (pre-, post-, and simultaneous-mordant) for dyeing cotton and viscose with tea and turmeric extract, in case of $\mathrm{CH}$ the post mordant method showed a higher depth of shade, as well as color values, compared with the fabric dyed using the other two methods. This may be attributed to the grater complex forming ability of the metal ions with the dye molecule in this technique. Tea and turmeric have a very good substantively for cellulosic fiber. Thus, in the post mordanting method, the dye is adsorbed on to the fiber, followed by the formation of an insoluble complex with metal ions showing bathochromic shift. In case of the simultaneous-mordanting method, some of the dye 
is lost due to the formation of an insoluble complex in the dye bath itself, while during the pre-mordanting some of the mordant stripped out in the dye bath, which subsequently forms an insoluble complex with dye molecules in the dye solution. Thus, both these phenomena bring about a decrease in the effective dye concentration in the dye bath (Perkin R.M. and Catlow N.). However, when using microwave irradiation the simultaneous-mordanting method showed a higher depth of shade as well as K/S values. This may be attributed to the microwave irradiation. Microwave gives a uniform exposure to any material moved through it. Microwave irradiation produce intensive movement in the liquor, which considerably accelerates the dye molecules to penetrate into the fiber on the one hand, and on the other ensures significantly faster dye transport to the fiber than is possible through diffusion alone. This shown clearly by dyeing from stationary liquor, for the cotton and viscose fiber are more intensively colored at each point in time by faster dye transport under the effect of microwave irradiation on the fiber, and followed by quicker formation of an insoluble complex with metal ion in the same time.

Table 1: Effect of salt addition to the dye bath on the color strength of cotton and viscous fabric dyed with tea and turmeric as natural dyes

\begin{tabular}{|c|c|c|c|c|c|c|c|c|c|}
\hline \multirow{4}{*}{ Mordant } & \multirow{4}{*}{$\begin{array}{l}\text { Mordant } \\
\text { conc. g/l }\end{array}$} & \multicolumn{8}{|c|}{$\mathrm{K} / \mathrm{S}$} \\
\hline & & \multicolumn{4}{|c|}{ Cotton } & \multicolumn{4}{|c|}{ Viscose } \\
\hline & & \multicolumn{2}{|c|}{ Tea } & \multicolumn{2}{|c|}{ Turmeric } & \multicolumn{2}{|c|}{ Tea } & \multicolumn{2}{|c|}{ Turmeric } \\
\hline & & $\mathrm{CH}$ & MW & $\mathrm{CH}$ & MW & $\mathrm{CH}$ & MW & $\mathrm{CH}$ & MW \\
\hline Control & 0 & 8.1 & 8.8 & 8.7 & 10.7 & 8.9 & 11.3 & 9.3 & 11.7 \\
\hline \multicolumn{10}{|c|}{ Pre-mordant } \\
\hline \multirow[t]{2}{*}{ Alum } & 5 & 8.3 & 8.5 & 8.6 & 10.9 & 9.1 & 11.3 & 9.7 & 11.8 \\
\hline & 10 & 9.5 & 9.9 & 9.7 & 11.1 & 9.9 & 11.5 & 10.1 & 12.1 \\
\hline \multirow[t]{2}{*}{ Copper } & 5 & 7.5 & 7.6 & 7.7 & 7.8 & 7.1 & 9.9 & 9.1 & 9.6 \\
\hline & 10 & 8.3 & 8.8 & 8.6 & 8.9 & 7.6 & 10.4 & 9.4 & 9.9 \\
\hline \multirow[t]{2}{*}{ Iron } & 5 & 7.0 & 6.3 & 7.2 & 6.1 & 6.6 & 7.1 & 7.4 & 8.3 \\
\hline & 10 & 7.7 & 7.1 & 8.3 & 6.6 & 7.2 & 7.6 & 7.6 & 8.9 \\
\hline \multicolumn{10}{|c|}{ simultaneous-mordantt } \\
\hline \multirow[t]{2}{*}{ Alum } & 5 & 8.3 & 9.9 & 8.0 & 11.4 & 8.6 & 11.7 & 9.6 & 11.9 \\
\hline & 10 & 9.9 & 10.3 & 9.5 & 11.9 & 10.1 & 12.6 & 10.4 & 12.3 \\
\hline \multirow[t]{2}{*}{ Copper } & 5 & 7.2 & 8.4 & 6.6 & 8.8 & 7.4 & 9.2 & 6.4 & 9.8 \\
\hline & 10 & 7.9 & 9.1 & 7.4 & 9.6 & 8.3 & 9.8 & 7.7 & 10.4 \\
\hline \multirow[t]{2}{*}{ Iron } & 5 & 6.3 & 7.8 & 5.3 & 7.3 & 5.8 & 8.2 & 7.5 & 8.2 \\
\hline & 10 & 7.1 & 8.4 & 6.2 & 8.6 & 7.0 & 8.7 & 7.9 & 8.7 \\
\hline \multicolumn{10}{|c|}{ Post-mordant } \\
\hline \multirow[t]{2}{*}{ Alum } & 5 & 8.9 & 8.8 & 9.2 & 10.2 & 8.7 & 10.8 & 9.9 & 11.1 \\
\hline & 10 & 10.3 & 10.1 & 10.5 & 10.7 & 10.1 & 11.4 & 10.3 & 11.8 \\
\hline \multirow[t]{2}{*}{ Copper } & 5 & 8.1 & 8.6 & 8.4 & 8.8 & 8.6 & 10.3 & 8.9 & 9.2 \\
\hline & 10 & 8.7 & 9.2 & 8.5 & 9.3 & 9.0 & 10.6 & 9.4 & 9.6 \\
\hline \multirow[t]{2}{*}{ Iron } & 5 & 7.4 & 6.5 & 7.7 & 7.1 & 7.7 & 8.4 & 8.7 & 7.7 \\
\hline & 10 & 8.3 & 7.9 & 8.5 & 7.8 & 8.5 & 8.7 & 9.1 & 8.4 \\
\hline
\end{tabular}

Dye condition: L.R.50:1, for MW: 10\%w/v for tea, $40 \mathrm{~min}$., $8 \% \mathrm{w} / \mathrm{v}$ for turmeric, $50 \mathrm{~min} ., \mathrm{pH}$ 4, for $\mathrm{CH}: 12 \% \mathrm{w} / \mathrm{v}$ for tea $\mathrm{pH} 5.5,110 \mathrm{~min}$., $8 \% \mathrm{w} / \mathrm{v}$ for turmeric $\mathrm{pH} 6,100 \mathrm{~min}$. 


\section{Kinetics of dyeing}

It is known that rate of any process means a change in one of the starting materials that takes place in the process or the product that obtained per unit time. Applying this definition in the dyeing process can be regarded as the change in the dye uptake per unit time. Time-dye uptake isotherms of cotton and viscose fabric using microwavey and conventionally dyed with tea and turmeric are shown in Fig. 10 and 11. The figure shows that the dye uptake values of microwave dyed samples are generally better than those dyed by conventional heating method. The isotherms of both methods started to be diffrentiated from each other to show better dye uptake for tea and turmeric dye under microwave heating in comparison with conventional heating.
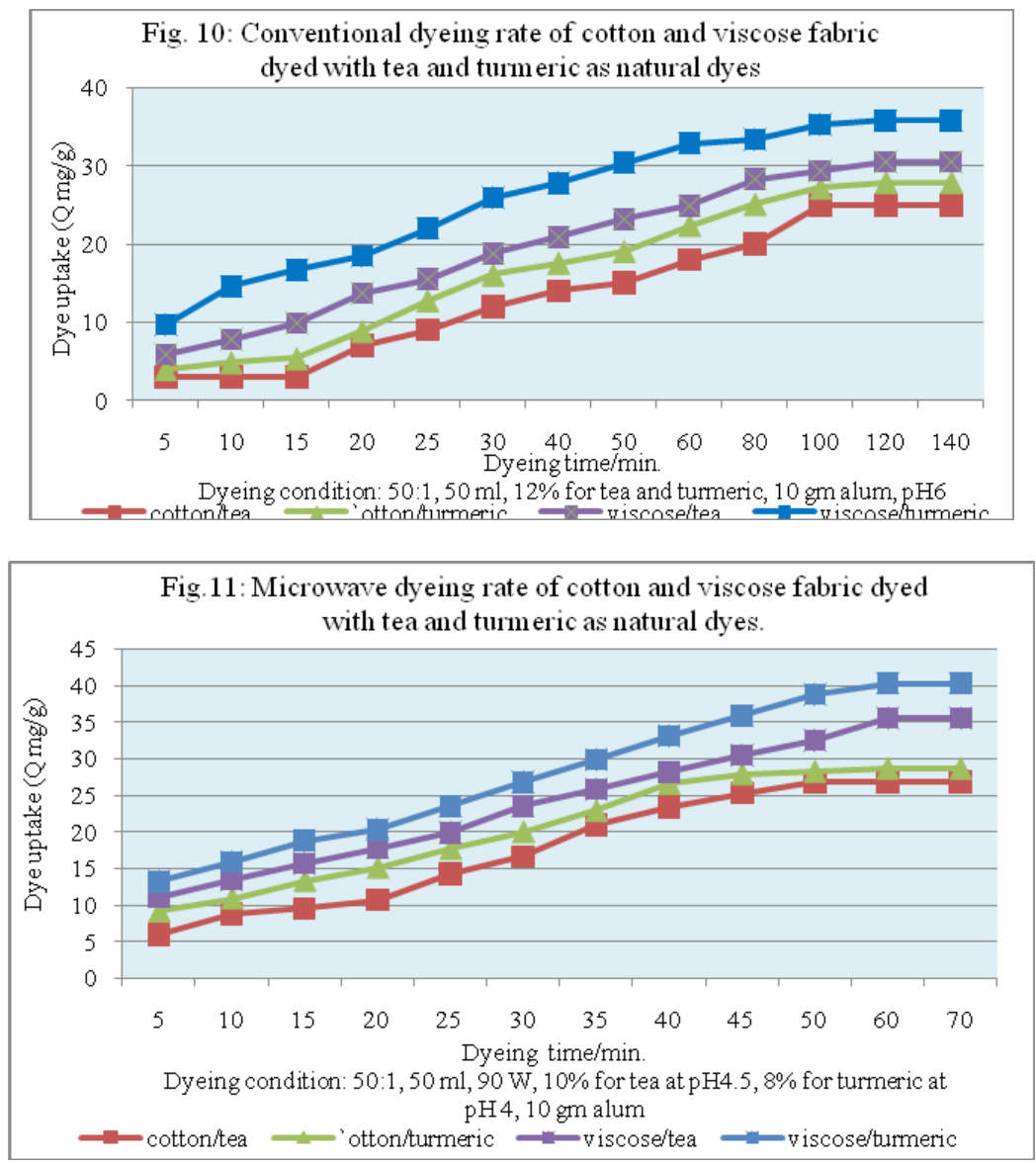
Generally, the dyeing process is a solid/liquid phase proceeds, which process by the movement of the dye molecules from liquid phase to the solid surface of the fibre by virtue of their affinity, and, once the dye molecule get into the fibre, the second slow process, which is diffusion controlled, start to take place. Acoordingly, the influnce of microwave power on the rate of dyeing would become clear in the diffusion process to reveal higher dye uptake in short time for microwave dyed samples in comparison with conventionally dyed ones. This enhancement may be attributed to microwave irradiation. One of the main features which distinguishes microwave heating from convective heating process is that because liquids absorb the bulk of the electromagnetic energy at microwave frequencies, the energy is transmitted directly to the wet material. The process does not rely on conduction of heat from the surface of the product and thus increased heat transfer occurs, speeding up the heating process (HTDEO and B.K.Desia, 1999).

The data in Fig. 10 and 11 can be analyzed by using the derivable general form of the first order rate equation (2) (Gupta D, Kumari S and Gulrajani M., 2001).

$$
\frac{A_{t}-A_{f}}{A_{0}-A_{f}}=e^{-\mathrm{kt}}
$$

Where:

$\boldsymbol{A}_{t}$ is the absorbance at time $t, \boldsymbol{A}_{0}$ is the initial absorbance, $\boldsymbol{A}_{\boldsymbol{f}}$ is the final absorbance, $\mathrm{t}$ is the reaction time and $\mathrm{k}$ is the reaction rate. Since the absorbance of solution is directly related to the concentration by Lambert-Beer law, therefore, equation (2) can be rewritten in terms of dye uptake to give equation (3):

$$
\frac{Q_{t}-Q_{f}}{Q_{o}-Q_{f}}=e^{-\mathrm{kt}}
$$

Where:

$Q_{t}$ is the dye uptake at time $t, Q_{0}$ is the dye uptake at zero time and $Q_{f}$ is the final dye uptake, $t$ is the dyeing time and $\mathrm{k}$ is the dyeing rate. Taking the logarithm of equation (3) would lead to equation (4) and since $Q$ is known, $Q_{t}-Q_{f}$ can be calculated.

$$
\ln \left|Q_{t}-Q_{f}\right|=\ln \left|Q_{o}-Q_{t}\right|-\mathrm{Kt}
$$


A plot of $\ln Q_{t}-Q_{f}$ vs. time is expected to be linear with a slope of $-\mathrm{k}$ and an intercepted of $\ln Q_{0}-Q_{t}$ if the reaction is first order.

Fig.12 and 13 shows the plot of $\ln Q_{t}-Q_{f}$ as a function of time for deying of cotton and viscose fabric with tea and turmeric dye using microwave and conventional heating methods. As can be seen in this figure the linear fitting of equation 4 holds indeed and the values of dyeing rate constant could be obtained as listed in Table 2 and 3.

The time of half dyeing $t_{1 / 2}$, which is the time required for the fabric to take up half of the amount of dye taken at equilibrium, is stimated from each isotherm directly (Fig.11) and or from the following equation 5 :

$$
\mathrm{t}_{1 / 2}=\ln 2 / \mathrm{k}
$$

The values of half dyeing time $t_{1 / 2}$ are given in Table 2 and 3 . The rate constant of dyeing cotton and viscose with tea and turmeric is clearly increased with microwave irradiation in comparison with conventional heating. Also, the values of $\mathbf{t}_{\frac{1}{2}}$ of dyeing are clearly short for those samples dyed with microwave in comparison with those dyed conventionally.

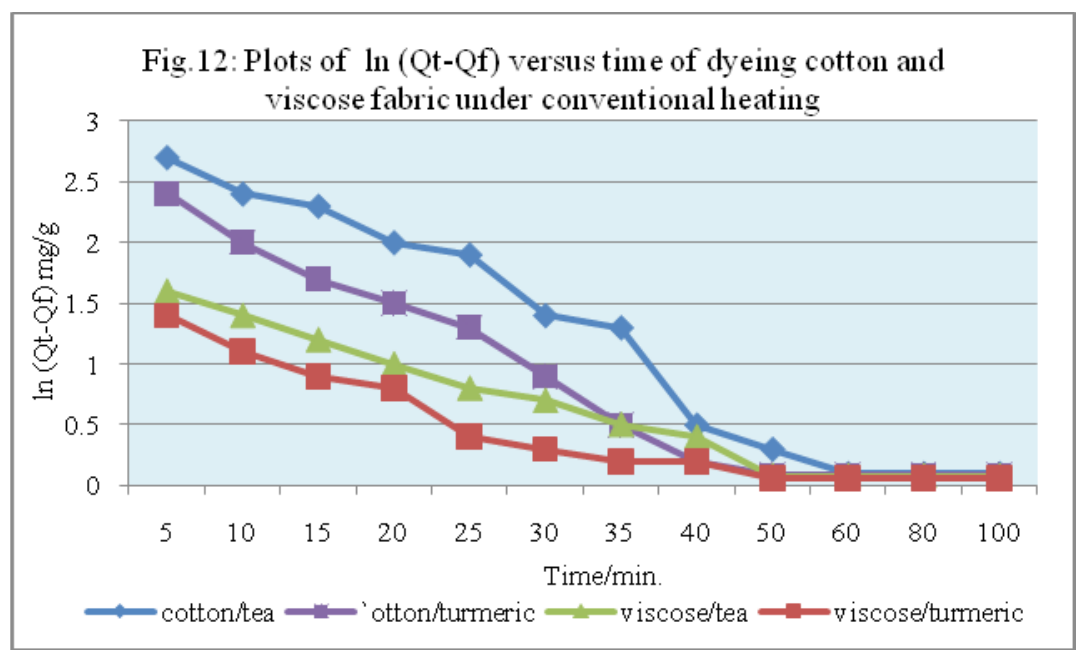




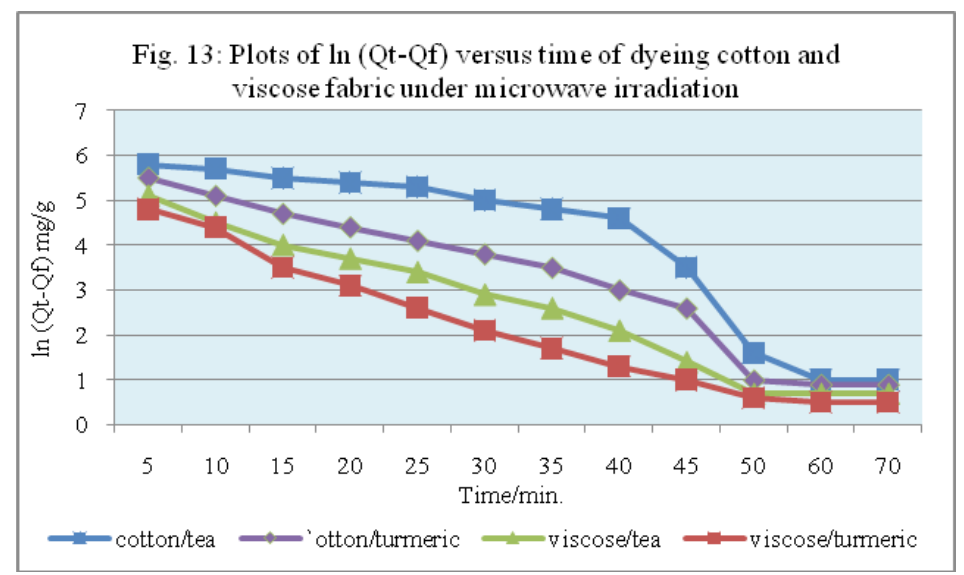

\section{Standard affinity}

The data for dyeing equlibrium are generally reported as the standard affinity of dyeing, $-\mathbf{\Delta} \boldsymbol{\mu}$. It has been reported that the dyeing of cotton and viscose fibres using natural dyes follow the same mechanism as that of disperse dyes, i.e.via partition mechanism (Gupta D, Kumari S and Gulrajani M.(2001). Therefore, the standard affinity can be calculated using equation (6):

$$
\text { - } \Delta \mu=R T \ln \frac{|C|_{t}}{[C\rfloor_{S}}
$$

Where $R$ is the gas constant, $T$ is the absolute temperature $(\mathrm{k}),[C]_{f}$ and $[C]_{s}$ are dye concentrations in the fiber and the dye bath, respectively. From Table 2 and 3 it can be seen that the standard affinity of cotton and viscose fiber in the case of MW is higher than the case of $\mathrm{CH}$. This is another evidance for the enhancement effect of microwave irradiation, increasing the affinity of tea and turmeric toward cotton and viscose fabric in comparison with convintional heating.

Table 2: Dyeing rate constant $k$, efficiency of microwave $\Delta K$, half dyeing time $t_{1 / 2}$, standard affinity $-\Delta \mu$, and amount of final dye uptake by cotton fabric dyed with tea and turmeric dye.

\begin{tabular}{|c|c|c|c|c|c|c|c|c|c|c|c|c|c|c|c|c|c|}
\hline \multicolumn{9}{|c|}{ Tea } & \multicolumn{9}{|c|}{ Turmeric } \\
\hline \multicolumn{2}{|c|}{$\begin{array}{c}\text { Kx100 } \\
\text { (min.-1) }\end{array}$} & \multirow[t]{2}{*}{\begin{tabular}{|c|}
$\Delta \mathrm{K}$ \\
$\%$
\end{tabular}} & \multicolumn{2}{|c|}{$\begin{array}{c}-\Delta \mu \\
(\mathrm{KJ} / \mathrm{mol})\end{array}$} & \multicolumn{2}{|c|}{$\begin{array}{c}t 1 / 2 \\
(\mathrm{~min})\end{array}$} & \multicolumn{2}{|c|}{$\begin{array}{l}\text { Qf (m } \\
\text { (mg/g) }\end{array}$} & \multicolumn{2}{|c|}{$\begin{array}{l}\text { Kx100 } \\
(\min -1)\end{array}$} & \multirow[t]{2}{*}{$\begin{array}{c}\Delta \mathrm{K} \\
\%\end{array}$} & \multicolumn{2}{|c|}{$\begin{array}{c}-\Delta \boldsymbol{\mu} \\
(\mathrm{KJ} / \mathrm{mol})\end{array}$} & \multicolumn{2}{|c|}{$\begin{array}{c}t 1 / 2 \\
\text { (min) }\end{array}$} & \multicolumn{2}{|c|}{$\begin{array}{c}\text { Qf } \\
(\mathrm{mg} / \mathrm{g})\end{array}$} \\
\hline CH & MW & & $\mathrm{CH}$ & MW & $\mathrm{CH}$ & MW & $\mathrm{CH}$ & MW & $\mathrm{CH}$ & MW & & $\mathrm{CH}$ & MW & $\mathrm{CH}$ & MW & $\mathrm{CH}$ & MW \\
\hline 3 & 6.7 & 66 & -107.3 & \begin{tabular}{|l|}
-202.8 \\
\end{tabular} & 3.3 & 1.03 & 123 & 113 & 2 & 5.1 & 49 & -155.8 & -244.4 & 4.95 & \begin{tabular}{|l|}
1.51 \\
\end{tabular} & 142 & 123 \\
\hline
\end{tabular}


Table 3: Dyeing rate constant $k$, efficiency of microwave $\Delta K$, half dyeing time $t 1 / 2$, standard affinity $-\Delta \mu$, and amount of final dye uptake by viscous fabric dyed with tea and turmeric dye.

\begin{tabular}{|c|c|c|c|c|c|c|c|c|c|c|c|c|c|c|c|c|c|}
\hline \multicolumn{9}{|c|}{ Tea } & \multicolumn{9}{|c|}{ Turmeric } \\
\hline \multicolumn{2}{|c|}{$\begin{array}{l}\text { Kx100 } \\
\text { (min.-1) } \\
\text { (min-1) }\end{array}$} & \multirow[t]{2}{*}{$\begin{array}{l}\Delta \mathrm{K} \\
\%\end{array}$} & \multicolumn{2}{|c|}{$\begin{array}{c}-\Delta \boldsymbol{\mu} \\
(\mathrm{KJ} / \mathrm{mol})\end{array}$} & \multicolumn{2}{|c|}{\begin{tabular}{|c}
$\mathbf{t 1} / \mathbf{2}$ \\
$(\mathrm{min})$ \\
$(\mathrm{min})$
\end{tabular}} & \multicolumn{2}{|c|}{$\underset{(\mathrm{mg} / \mathrm{g})}{\mathrm{Qf}}(\mathrm{m}$} & \multicolumn{2}{|c|}{$\begin{array}{l}{ }_{(\mathrm{m}} \mathrm{Kx} 100 \\
(\mathrm{~min}-1)\end{array}$} & \multirow[t]{2}{*}{$\begin{array}{l}\Delta \mathrm{K} \\
\%\end{array}$} & \multicolumn{2}{|c|}{$\begin{array}{c}-\Delta \boldsymbol{\mu} \\
(\mathrm{KJ} / \mathrm{mol})\end{array}$} & \multicolumn{2}{|c|}{\begin{tabular}{|c|}
$t 1 / 2$ \\
$(\min )$ \\
$(\min )$
\end{tabular}} & \multicolumn{2}{|c|}{\begin{tabular}{|c|}
$\mathrm{Qf}$ \\
$(\mathrm{mg} / \mathrm{g})$
\end{tabular}} \\
\hline $\mathrm{CH}$ & MW & & $\mathrm{CH}$ & MW & $\mathrm{CH}$ & MW & $\mathrm{CH}$ & MW & $\mathrm{CH}$ & MW & & $\mathrm{CH}$ & MW & $\mathrm{CH}$ & MW & $\mathrm{CH}$ & MW \\
\hline 2 & 7.1 & 61 & -152.1 & -325.8 & 4.95 & 2.17 & 112 & 96 & 2 & 5.2 & 42 & -184.5 & -365.3 & 9.9 & 2.9 & 153 & 98 \\
\hline
\end{tabular}

\section{Fastens properties}

Fastness properties of the MW and $\mathrm{CH}$ methods dyed fabric are shown in table 4, 5. The washing, perspiration, rubbing and light fastens value of cotton and viscous fabric showed fair to good fastness in case of the dyed samples using both MW and $\mathrm{CH}$ heating method. While in case of MW heating show excellent fastness to light than CH dyed fabric. (Tera Light Fastness Tester).

\section{Table 4: Fastness properties of dyed cotton fabric by tea and} turmeric as natural dyes.

\begin{tabular}{|c|c|c|c|c|c|c|c|c|c|c|c|c|}
\hline \multirow{3}{*}{\begin{tabular}{|l} 
Dyeing \\
technique
\end{tabular}} & \multirow{2}{*}{\multicolumn{3}{|c|}{ Washing }} & \multicolumn{6}{|c|}{ Perspiration } & \multirow{2}{*}{\multicolumn{2}{|c|}{ Rubbing }} & \multirow{3}{*}{$\begin{array}{l}\text { Light } \\
\text { fastness }\end{array}$} \\
\hline & & & & \multicolumn{3}{|c|}{ Acid } & \multicolumn{3}{|c|}{ Alkaline } & & & \\
\hline & Alt. & $\mathrm{St}^{*}$ & $\mathrm{St}^{* *}$ & Alt. & $\mathrm{St}^{*}$ & $\mathrm{St}^{* *}$ & Alt. & St* & $\mathrm{St} * *$ & Dry & Wet & \\
\hline \multicolumn{13}{|c|}{ Tea } \\
\hline $\mathrm{CH}$ & \begin{tabular}{|l|}
$3-4$ \\
\end{tabular} & $2-3$ & 3 & $3-4$ & 3 & $2-3$ & \begin{tabular}{|l|}
$3-4$ \\
\end{tabular} & 3 & 4 & 3 & 2 & \begin{tabular}{|l|}
$44-5$ \\
\end{tabular} \\
\hline MW & 4 & 4 & 4 & $3-4$ & 4 & 4 & 4 & 3-4 & 4 & 4 & 3 & $5-6$ \\
\hline \multicolumn{13}{|c|}{ Turmeric } \\
\hline $\mathrm{CH}$ & 3 & $2-3$ & \begin{tabular}{|l|}
$2-3$ \\
\end{tabular} & 4 & 3 & 2 & $2-3$ & $2-3$ & 3 & $2-3$ & 2 & 5 \\
\hline $\mathrm{Mw}$ & 4 & 4 & 4 & 4 & $3-4$ & 3 & 4 & 4 & $3-4$ & 4 & 4 & $5-6$ \\
\hline
\end{tabular}

Where Alt. = change in color, $\mathrm{St}^{*}=$ straining on cotton, $\mathrm{St}^{* *}=$ straining on wool.

Table 5: Fastness properties of dyed viscous fabric by tea and turmeric as natural dyes.

\begin{tabular}{|c|c|c|c|c|c|c|c|c|c|c|c|c|}
\hline \multirow[t]{3}{*}{ Dyeing } & \multirow{2}{*}{\multicolumn{3}{|c|}{ Washing }} & \multicolumn{6}{|c|}{ Perspiration } & \multirow{2}{*}{\multicolumn{2}{|c|}{ Rubbing }} & \multirow{3}{*}{$\begin{array}{l}\text { Light } \\
\text { fastness }\end{array}$} \\
\hline & & & & \multicolumn{3}{|c|}{ Acid } & \multicolumn{3}{|c|}{ Alkaline } & & & \\
\hline & Alt. & $\mathrm{St}^{*}$ & $\mathrm{St} * *$ & Alt. & $\mathrm{St}^{*}$ & $\mathrm{St}^{* *}$ & Alt. & $\mathrm{St}^{*}$ & $\mathrm{St}^{* *}$ & Dry & Wet & \\
\hline \multicolumn{13}{|c|}{ Tea } \\
\hline $\mathrm{CH}$ & 3 & 3 & $2-3$ & 3 & $2-3$ & $2-3$ & $2-3$ & 3 & 3 & $2-3$ & 2 & $4-5$ \\
\hline MW & 3-4 & 4 & 4 & 4 & 4 & $3-4$ & $3-4$ & 4 & 4 & 3-4 & 4 & $4-5$ \\
\hline \multicolumn{13}{|c|}{ Turmeric } \\
\hline $\mathrm{CH}$ & $2-3$ & 3 & 3 & $2-3$ & $2-3$ & 3 & $2-3$ & $2-3$ & $2-3$ & $2-3$ & 2 & 4 \\
\hline $\mathrm{Mw}$ & 4 & $3-4$ & $3-4$ & 4 & 4 & 4 & 4 & 4 & 4 & 3-4 & 4 & $5-6$ \\
\hline
\end{tabular}

Where Alt. = change in color, $\mathrm{St}^{*}=$ straining on cotton, $\mathrm{St}^{* *}=$ straining on wool. 


\section{Conclusion}

The dyeing of cotton and viscose fabric using turmeric and tea as a natural dyes has been investigated in both conventional and microwave heating. The extractability of turmeric and tea from natural origin using microwave power was comparison with traditional heating. The results of dye extraction indicate that microwave power is rather effective than traditional heating at low concentration and short time. The standard affinity of cotton and viscose fiber in the case of MW is higher than the case of $\mathrm{CH}$. The values of $\mathbf{t} \mathbf{1} / \mathbf{2}$ of dyeing are clearly short for those samples dyed with microwave heating in comparison with those dyed conventionally. The washing, perspiration, rubbing and light fastens value of cotton and viscose fabric showed fair to good fastness in case of both $\mathrm{CH}$ and $\mathrm{MW}$ heating, while in case of light fastness MW heating show excellent fastness to light than $\mathrm{CH}$ dyed fabric. Microwave dyeing gives an even dye finish with a lustrous look and an even pattern of color. The advantages of dyeing in the microwave are:

1-It is environmental sound as one uses much less liquid and thus can exhaust dyes or save them and have no liquid dye waste to get rid of.

2 - Less power consumption.

3- Dyeing is quick as several minutes.

4 - Re-dyeing to desire shade is possible easily.

\section{Reference}

1. ASTM Designation; D.5035-90, Standard Test Method For Breaking Force and Elongation of Textile Fabrics (strip force) American Society for Testing and Materials.

2. BURNETT PHILIP, textile Horizon,p-35, February 1995.

3. E.G.TSATSARONI AND IC ELEFTHERIADIS, J.S.D.C., 110(1994) 313.

4. GLOVER BAND PIERO J.H., J.Soc. Dyers color, Vol.109, No.1, 5(1993).

5. GUPTA D, KUMARI S AND GULRAJANI M, colour. Technol.117: 333 (2001).

6. HTDEO AND B.K.DESIA; “Dyeing of cotton with natural dye”, JSDC, 115, 1999.

7. JOHNSON A, the theory of coloration of textiles, chap 4 . The society of dyers and colorists, Bradford (1989).

8. M. TSUJIMURA; Nippon Nogikagaku Kaishi, 10(1934) 140.

9. M.D. TELI, Roshan panl\&P.D. pardeshi, Clourage (2000) 43.

10. PERKIN R.M. AND CATLOW N.; JSDC 100,Sep.274 (1984). 
11. ROY TERANISHI AND IRWIN HORNTEIN, Food Rev. Int.(New York; Marcel Dekker,1995).

12. Tera Light Fastness Tester; (“TAFT” Egyptian’s patent office), Patent no.15182. 